\title{
THE 2017 ANNUAL JONATHAN TREJO-MATHYS ESSAY PRIZE
}

Jonathan Trejo-Mathys (1979-2014), a member of the Global Justice Network and assistant professor of philosophy at Boston College, worked in both philosophy and critical social theory. In his honour, The Global Justice Network annually awards the Jonathan Trejo-Mathys Essay Prize to recognize a stellar contribution to the political theory and philosophy of global justice. The prize is sponsored by the Clough Center for the Study of Constitutional Democracy at Boston College. The Network is very pleased to announce that the 2017 Prize has been awarded to Francisco Garcia Gibson, postdoctoral researcher at the National Research Council of Argentina (CONICET) and the Centro de Investigaciones Filosóficas (CIF) at the Universidad de Buenos Aires for his essay 'Guns or Food: On Prioritizing National Security over Global Poverty Relief'. The committee believes that the essay makes an important contribution to the scholarship in political theory, philosophy and international relations through its discussion of the normative commitments of political realism.

Honourable mentions were also awarded to Nicole Hassoun, Associate Professor at Binghampton University, for her piece on 'Fair Trade: An Imperfect Obligation?' and Anahi Wiedenbrüg, doctoral research student at the LSE, for her submission 'On the Responsibilities of Dominated States'.

All three papers are included in this edition in the section which follows: congratulations to all three authors.

- The Editors 